\title{
REAÇÃo DE HÍBRIDOS, LINHAGENS E PROGÊNIES DE PIMENTÃo À REQUEIMA CAUSADA POR Phytophthora capsici E AO MOSAICO AMARELO CAUSADO POR Pepper yellow mosaic vírus (PepYMV)
}

\author{
Reaction of hybrids, lines and progenies of sweet pepper the blight caused by \\ Phytophthora capsici and to Pepper yellow mosaic virus (PepYMV)
}

\author{
Ildon Rodrigues do Nascimento ${ }^{1}$, Luiz Artur Costa do Valle², Wilson Roberto Maluf ${ }^{3}$,Luciano Donizete Gonçalves ${ }^{1}$, \\ Luís Antônio Augusto Gomes ${ }^{3}$, Paulo Moreto ${ }^{4}$, Eloísa Aparecida das Graças Leite Lopes 5
}

\section{RESUMO}

A requeima do pimentão (Capsicum annuum L.) causada por Phytophthora capsici e o mosaico amarelo causado por PepYMV são prioridades nos programas de melhoramento de pimentão em andamento no Brasil. Foram avaliados três híbridos comerciais (Magali R, Atenas $\mathrm{F}_{1}$ e Fortuna Super $\mathrm{F}_{1}$ ), cinco linhagens, 20 híbridos experimentais e duas progênies $\mathrm{F}_{2 \cdot 4}$ do programa de melhoramento da Universidade Federal de Lavras/HortiAgro Sementes quanto à reação a $P$. capsici e a PepYMV. Os experimentos foram montados independentemente em blocos casualizados, com quatro e duas repetições, respectivamente. Cada parcela foi constituída de oito plantas instaladas em bandejas de 128 células, que foram mantidas em estufa com cobertura plástica e laterais teladas. As avaliações foram feitas do $4^{\circ}$ ao $14^{\circ}$ e do $15^{\circ}$ ao $40^{\circ}$ dias após a inoculação (DAI) para $P$. capsici e PepYMV, respectivamente. A inoculação com P. capsici foi feita por meio da distribuição de $5 \mathrm{~mL}$ de suspensão com $10^{4}$ zoósporos $/ \mathrm{mL}$ no solo ao redor do colo de cada planta. A inoculação mecânica de PepYMV foi feita a partir de macerados de folhas de Nicotiana tabacum cv. TNN, previamente infectadas. Os híbridos Magali R e Fortuna Super, foram suscetíveis a $P$. capsici, enquanto que o acesso Criollo de Morellos 334, a linhagem PIM-013 e as progênies PIX-03 pl\#03-2 e PIX-030 pl\#06-3 (ambas originadas do cruzamento com Criollo de Morellos), foram resistentes. Reação de resistência a $P$. capsici foi também observada para os híbridos experimentais que tiveram PIM-013 como uma das linhagens parentais. Criollo de Morellos 334, as progênies PIX-03 pl\#03-2 e PIX-030 pl\#06-3, o híbrido comercial Magali R e outros 6 híbridos experimentais que tinham como um dos genitores a linhagem MYR-29 forma ressitentes ao PepYMV. As progênies PIX-03 pl\#03-2 e PIX-030 pl\#06-3 são fontes promissoras de resistência a ambos os patógenos para serem desenvolvidas e exploradas em programas de melhoramento. PIM-013 e MYR-29 são fontes de resistência promissoras a $P$. capsici PepYMV, respectivamente, para serem utilizadas no desenvolvimento de híbridos com resistência a esses patógenos.

Termos para indexação: Capsicum annuum, Potyvirus, resistência, $\mathrm{PVY}^{\mathrm{M}}$, requeima.

\section{ABSTRACT}

Resistance to pepper blight induced by Phytophthora capsici and to yellow mosaic caused by a potyvirus species (PepYMV) are two priorities of most pepper (Capsicum annuum L.) breeding programmes in Brazil. The reactions of three commercial hybrids (Magali-R, Atenas F1, and Fortuna Super F1) to both P. capsici and PepYMV was studied, along with those of 20 experimental hybrids, 6 inbred lines and two F2:4 progenies from the Universidade Federal of Lavras pepper breeding programme. Trials in randomized complete block designs were carried out independently for each of the pathogens, with four and two replications, respectively. Each replications comprised 8 plants in 128-cell speeding styrofoam trays, kept in plastic-covered greenhouses protected with screen at the sides. Evaluation of symptoms was made from the 4th to the 14th and from the 15 th to the 40th day after inoculation (DAI) for P. capsici and PepYMV, respectively. Inoculation with $P$. capsici was made by dispensing $5 \mathrm{~mL}$ of a $10^{4}$ zoospore. $\mathrm{mL}^{-1}$ solution at the soil around the base of each plant. PepYMV was mechanically inoculated from extracts of previously infected leaves of TNN tobacco. Hybrids Magali-R and Fortuna Super were susceptible to P. capsici, while the hybrid Atenas, the access Criollo de Morellos 334, the progeny PIX-030 pl\#03-2 and PIX-030 pl\#06-3 (both originated from crosses with Criollo de Morellos), and the line PIM-013 were resistant. Among the experimental hybrids, three were also resistant to $P$. capsici, all three having PIM-013 as one of the parental lines. Resistance to PepYMV was found in Criollo de Morellos 334, progeny PIX-030 pl\#03-2 and PIX-030 pl\#06-3, and in the commercial hybrid Magali, besides 6 other experimental hybrids having line MYR-29 as one of the parental ines. The only treatment with resistance to both P. capsici and PepYMV were families PIX-030 pl\#03-2 and PIX-030 pl\#06-3, and the experimental hybrid F1(PIM-013 x MYR-29). Progeny PIX-030 pl\#03-2 and PIX-030 pl\#06-3 proved to be promissing sources of resistance to both pathogens to be deployed in breeding programmes. PIM-013 and MYR-29 are promissing sources of resistance to P. capsici and PepYMV, respectively, to be deployed in development of hybrids with resistance to these pathogens.

Index terms: Capsicum annuum, potyvirus, resistance, blight.

(Recebido para publicação em 3 de março de 2005 e aprovado em 18 de outubro de 2005)

\footnotetext{
${ }^{1}$ CEDETEG/DEAGRO - UNICENTRO - Rua Simeão Camargo Varela de Sá, no 03 - Cx. P. 3010 - 84040-080 - Guarapuava, PR nascimento_ildon@yahoo.com.br

${ }^{2}$ Ministério da Agricultura Pecuária e Abastecimento - Laboratório de Análise de Sementes Oficial Supervisor - Av. Raja Gabaglia, 245 - Cidade Jardim 30380-090 - Belo Horizonte, MG - luizvalle@agricultura.gov.br

${ }^{3}$ Professores do Departamento de Agricultura/DAG - Universidade Federal de Lavras /UFLA - Cx. P. 3037 - 37.200-000 - Lavras, MG - wrmaluf@ufla.br ${ }^{4}$ HortiAgro Sementes Ltda.

${ }^{5}$ Departamento de Fitopatologia/DFP - Universidade Federal de Lavras /UFLA - Cx. P. 3037 - 37.200-000 - Lavras, MG.
} 


\section{INTRODUÇÃO}

As doenças requeima ou mela do pimentão (Phytophthora capsici, Leonian) e viroses causadas por Potyvirus, particularmente pela espécie PepYMV (Pepper yellow mosaic vírus), têm sido ultimamente prioridade nos programas de melhoramento de pimentão no Brasil (ECHER \& COSTA, 2002; MACIEL-ZAMBOLIM et al., 2004; REIFSCHNEIDER, 2000; VALLE, 2001).

Phytophthora capsici (Leonian, 1922) é o agente causal da mais importante doença do pimentão no Brasil e no mundo, sendo capaz também de causar doença em espécies de outros quarenta gêneros de plantas (LUZ et al., 2003). No campo a doença é devastadora, mas pode provocar prejuízos também no armazenamento (GUBLER \& DAVIS, 1996).

Por ser considerado um patógeno de solo, a fase mais crítica da doença é a fase radicular. Nesta fase, a presença de alta umidade e hospedeiros suscetíveis contribuem para tornar o controle químico pouco eficiente (RISTAINO \& JOHNSTON, 1999). Apesar dessa dificuldade, em condições de cultivo, essa tem sido a alternativa mais utilizada pelos produtores (CAFÉ FILHO et al., 1995).

A utilização de genótipos com diferentes níveis de resistência, especialmente na fase mais crítica (resistência juvenil), pode contribuir para reduzir os prejuízos causados pela doença (HENZ \& LIMA, 1994). Entretanto, pesquisas para identificação, seleção e uso de novas fontes de resistência no gênero Capsicum à $P$. capsici no Brasil têm sido relativamente escassas, principalmente quando se considera o desenvolvimento de linhagens para serem exploradas em combinações híbridas.

Várias fontes de resistência genética para controle da doença têm sido testadas, porém, os resultados na literatura quanto à natureza genética da resistência são variáveis (GIL-ORTEGA et al., 1991, 1992, 1995; KOBORI et al., 2000; PRINCE et al., 2001; REIFSCHNEIDER, 2000; SARAIVA, 1982). Resistência do tipo completa e conferida por alelos de poucos genes, alguns de natureza dominante sob efeito de modificadores, tem sido relatado no acesso 'Criollo Morellos - 334 (CM-334)', em trabalhos realizados tanto no Brasil como em outros países (GIL-ORTEGA et al., 1991, 1992, 1995; GUERRERO-MORENO \& LOBORDE, 1980; KOBORI et al., 2000; PALLOIX et al., 1988). Linhagens promissoras provenientes de CM-334 constituem importantes fontes de resistência genética à $P$. capsici, entretanto, as reações dessas linhagens em diferentes combinações híbridas não foram até o momento avaliadas.
Segundo Truta et al., (2004), as espécies de vírus do gênero Potyvirus ocorrendo em pimentão em todo o mundo são: Potato vírus Y (PVY); Tobacco etch vírus (TEV); Pepper veinal motle vírus (PVMV); Chilli veinal motle virus (ChiVMV); e Pepper yellow mosaic vírus (PepYMV). No Brasil, a espécie PepYMV atualmente é de ocorrência natural nas principais regiões produtoras, provocando a doença conhecida vulgarmente como mosaico amarelo do pimentão. No Espírito Santo, essa espécie foi relatada também em plantios comercias de tomateiro (MACIEL-ZAMBOLIM et al., 2004).

A primeira ocorrência de PepYMV data da década de 1980, quando foi denominada de $\mathrm{PVY}^{\mathrm{M}}$ (BOITEUX et al., 1996). Ultimamente, estudos moleculares demonstraram que se tratava de uma nova espécie do gênero Potyvirus, agora denominada de PepYMV (Pepper yellow mosaic virus) (INOUE-NAGATA et al., 2002).

Fontes de resistência genética a PepYMV no gênero Capsicum têm se mostrado eficientes e duradouras em condições de inoculação artificial e em nível de campo (CARANTA et al., 1999; ECHER \& COSTA, 2002; KYLE \& PALLOIX, 1997). Resistência genética do tipo monogênica e dominante vem sendo utilizada em híbridos, como por exemplo, a cultivar híbrida Magali R (Sakata Sudamerica), tida como padrão comercial de resistência a tal doença (TRUTA et al., 2004). No acesso CM-334, nos híbridos Nathalie e Reinger e nas cultivares de polinização livre Myr-29 e Myr-10 tem sido relatada também a ocorrência de resistência genética do tipo monogênica (ECHER \& COSTA, 2002; VALLE, 2001). Alguns autores comentam que a reação de resistência do pimentão a espécies do gênero Potyvirus é devida à ação do gene dominante $P v r$ 4 ou de outros genes da série $P v r$ (CARANTA et al., 1999; ECHER \& COSTA, 2002; KYLE \& PALLOIX, 1997).

Novos híbridos, linhagens e algumas progênies experimentais de pimentão foram desenvolvidos pelo Programa de Melhoramento Genético de Hortaliças da Universidade Federal de Lavras/HortiAgro Sementes Ltda, mas não foram avaliados quanto à reação a $P$. capsici e a PepYMV. Como a resistência a esses dois patógenos é um dos objetivos do melhoramento de pimentão, este trabalho teve por objetivo realizar essa avaliação.

\section{MATERIAL E MÉTODOS}

\section{Detalhes experimentais}

Os experimentos foram realizados em casa-devegetação, na estação Experimental da HortiAgro Sementes Ltda., situada no município de Ijaci-MG. Os híbridos, 
linhagens e progênies $\mathrm{F}_{2: 4}$ avaliados estão listados nas tabelas 1 e 2. Para ambos os experimentos, a semeadura foi realizada em caixas plásticas com uma mistura de casca de arroz carbonizada e substrato comercial Plantimaxâ na proporção 1:1. Após a emergência, procedeu-se à repicagem para bandejas de isopor de 128 células $(16$ x 8) com a mesma mistura. Os experimentos foram montados independentemente em delineamento em blocos casualizados, com quatro e duas repetições para $P$. capsici e PepYMV, respectivamente. Em ambos os casos, as parcelas foram constituídas de oito plantas. Antes e após a inoculação, as bandejas foram mantidas em estufa com cobertura plástica e laterais teladas.

\section{Inoculação e avaliação das plantas para Phytophthora capsici}

O isolado utilizado (Bahamas) foi obtido por Valle (2001), a partir de um fruto de pimentão infectado coletado em supermercado da cidade de Viçosa - MG. A manutenção e produção do inóculo foi feita de acordo com Urben (1980). Para produção de esporângios, o isolado foi cultivado em meio suco de tomate-agar $(200 \mathrm{~mL}$ de suco de tomate Superbom, $3 \mathrm{~g}$ de carbonato de cálcio, $17 \mathrm{~g}$ de ágar e 800 $\mathrm{mL}$ de água destilada), a $28^{\circ} \mathrm{C}$, sob luz contínua, por sete dias. A seguir, adicionaram-se $10-15 \mathrm{~mL}$ de água destilada por placa e efetuou-se uma leve raspagem com alça de Drigalsky para destacar os esporângios. Para liberação de zoósporos, a suspensão foi deixada em temperatura ambiente por cerca de uma hora e então filtrada em camada dupla de gaze. Uma amostra de $5 \mathrm{~mL}$ da suspensão de zoósporos agitada em "Vortex" para mobilizar os zoósporos. Em seguida, a concentração foi determinada em hemacitômetro e ajustada para $10^{4}$ zoósporos $/ \mathrm{mL}$ por diluição do restante da suspensão.

A inoculação foi realizada aos 48 dias após a repicagem das plântulas mediante a distribuição de $5 \mathrm{~mL}$ da suspensão (concentração $10^{4}$ zoósporos/mL) na superfície do substrato de cada célula na bandeja. Para manter o substrato úmido, as bandejas foram irrigadas 30 minutos antes da inoculação. Foram feitas seis avaliações do $4^{\circ}$ ao $14^{\circ}$ dia após a inoculação (DAI), registrando-se a porcentagem de incidência de necrose no coleto, murcha e morte da planta em cada parcela.

\section{Inoculação e avaliação das plantas para PepYMV}

O isolado viral foi cedido aos autores pela empresa Sakata Sudamerica, oriundo da região de Lins - SP, de plantas com sintoma sistêmico e naturalmente infectadas. Embora estivesse rotulado como PVY, esse isolado não reagiu em testes ELISA com o anti-soro policlonal para PVY do Centro de Indexação de Viroses da UFLA em quatro tentativas. Ao mesmo tempo, material vegetal de plantas infectadas da cultivar Magda foi enviado para o laboratório de virologia da Embrapa Hortaliças, Brasília - DF, aos cuidados da Dr ${ }^{a}$. Alice K. Inoue Nagata, reagindo positivamente para o anti-soro de PepYMV.

Para manutenção do isolado, folhas de plantas de Nicotiana tabacum cv. TNN e de pimentão cv. Magda foram armazenadas em nitrogênio líquido. A multiplicação do inóculo foi feita em plantas de Nicotiana tabacum cv. TNN mantidas em estufas teladas, renovadas em intervalos não superiores a dois meses.

Para inoculação, as plantas de pimentão nas bandejas foram primeiramente aspergidas com carborundum (400 mesh). Em seguida foi obtido um macerado de folhas de Nicotiana tabacum cv. TNN infectadas com PepYMV em tampão fosfato $0,01 \mathrm{M}, \mathrm{pH}$ 7,0 . Esse macerado vegetal foi aplicado com o polegar nas folhas das plantas de pimentão. As inoculações mecânicas foram feitas aos 22 dias e repetidas aos 27 dias após a repicagem. Após a inoculação, as plantas foram irrigadas e mantidas em estufas com cobertura plástica e laterais teladas.

As avaliações foram feitas semanalmente do $15^{\circ}$ ao $40^{\circ}$ dia após a primeira inoculação. Para cada planta foi atribuída notas, variando de 1 a 5, sendo: 1=sem sintomas; 2=clareamento de nervuras; $3=$ mosaico leve; $4=$ mosaico bem desenvolvido, sem deformação foliar; 5=mosaico amarelo, bolhoso, com deformação foliar. Realizou-se análise de grupamento, sendo considerados suscetíveis os genótipos com notas superiores a 2,0.

\section{RESULTADOS E DISCUSSÃO}

No experimento para avaliação da reação a Phytophthora capsici, os sintomas iniciais nas plantas suscetíveis consistiram de lesões iniciais no colo, escurecimento das raízes e do caule, com posterior morte das plantas. As linhagens utilizadas como testemunhas suscetíveis apresentaram $100 \%$ de incidência de doença ao final do experimento, confirmando a eficácia da inoculação e da concentração de inóculo utilizada (Tabela 1). As testemunhas resistentes, exceto a linhagem PIM-013 (11,4\% de incidência, em média), não apresentaram qualquer planta doente. Por outro lado, os híbridos comerciais (Magali-R e Fortuna Super) e a maioria dos híbridos experimentais apresentaram 100\% de incidência de doença ao final do experimento. 
TABELA 1 - Incidência de necrose do colo e murcha em mudas de pimentão inoculadas com Phytophthora capsici em bandejas de isopor de 128 células.

\begin{tabular}{|c|c|c|c|c|}
\hline Materiais testados & Tipo & Incidência $(\%)^{1,2}$ & Desvio Padrão & Reação $^{3}$ \\
\hline \multicolumn{5}{|l|}{ Testemunhas resistentes: } \\
\hline Criollo de Morelos 334 & Linhagem & 0,0 & 0,0 & $\mathrm{R}$ \\
\hline PIM-013 & Linhagem & 11,4 & 15,6 & $\mathrm{R}$ \\
\hline PIX-030 pl\#03-2 & Progênie $F_{2: 4}$ & 0,0 & 0,0 & $\mathrm{R}$ \\
\hline PIX-030 pl\#06-3 & Progênie $F_{2: 4}$ & 0,0 & 0,0 & $\mathrm{R}$ \\
\hline \multicolumn{5}{|l|}{ Testemunhas suscetíveis: } \\
\hline PIM-014 & Linhagem & 100,0 & 0,0 & $\mathrm{~S}$ \\
\hline LINHA-003 & Linhagem & 100,0 & 0,0 & $\mathrm{~S}$ \\
\hline LINHA-004 & Linhagem & 100,0 & 0,0 & $\mathrm{~S}$ \\
\hline LINHA-006 & Linhagem & 100,0 & 0,0 & $\mathrm{~S}$ \\
\hline \multicolumn{5}{|l|}{ Híbridos avaliados: } \\
\hline Magali-R F1 (Sakata Sudamerica) & Híb. Comercial & 100,0 & 0,0 & $\mathrm{~S}$ \\
\hline Fortuna Super F1 (Agristar) & Híb. Comercial & 100,0 & 0,0 & $\mathrm{~S}$ \\
\hline F1(HERCULES x L-004) & Híb. Experimental & 100,0 & 0,0 & $\mathrm{~S}$ \\
\hline F1 (L006 x L004) & Híb. Experimental & 100,0 & 0,0 & $\mathrm{~S}$ \\
\hline F1(L-3509 x L-004) & Híb. Experimental & 100,0 & 0,0 & $S$ \\
\hline F1(L-005 x L-004) & Híb. Experimental & 93,8 & 12,5 & $\mathrm{~S}$ \\
\hline F1(L-005 x L-006) & Híb. Experimental & 100,0 & 0,0 & $\mathrm{~S}$ \\
\hline F1(L-005 x MYR-29) & Híb. Experimental & 90,6 & 12,0 & $\mathrm{~S}$ \\
\hline Atenas F1 (Seminis) & Híb. Comercial & 12,5 & 17,7 & $\mathrm{R}$ \\
\hline F1(PIM-013 x L-004) & Híb. Experimental & 18,8 & 16,1 & $\mathrm{R}$ \\
\hline F1(PIM-013 x L-006) & Híb. Experimental & 6,3 & 12,5 & $\mathrm{R}$ \\
\hline F1(PIM-013 x MYR-29) & Híb. Experimental & 0,0 & 0,0 & $\mathrm{R}$ \\
\hline F1(PIM-014 x L-004) & Híb. Experimental & 100,0 & 0,0 & $\mathrm{~S}$ \\
\hline F1(PIM-014 x L-006) & Híb. Experimental & 100,0 & 0,0 & $\mathrm{~S}$ \\
\hline F1(PIM-014 x MYR-29) & Híb. Experimental & 100,0 & 0,0 & $S$ \\
\hline F1(MAGDA x L-004) & Híb. Experimental & 100,0 & 0,0 & $\mathrm{~S}$ \\
\hline F1(MAGDA x L-006) & Híb. Experimental & 100,0 & 0,0 & S \\
\hline F1(MAGDA x MYR-29) & Híb. Experimental & 100,0 & 0,0 & $\mathrm{~S}$ \\
\hline F1(PIX-021G 0818 pl\#01 x L-004) & Híb. Experimental & 100,0 & 0,0 & $\mathrm{~S}$ \\
\hline F1(PIX-021G 0818 pl\#01 x L-006) & Híb. Experimental & 100,0 & 0,0 & $\mathrm{~S}$ \\
\hline F1(PIX-021G 0818 pl\#01 x MYR-29) & Híb. Experimental & 100,0 & 0,0 & $\mathrm{~S}$ \\
\hline F1(PIX-022E31 pl\#14 x L-004) & Híb. Experimental & 100,0 & 0,0 & $\mathrm{~S}$ \\
\hline F1(PIX-022E31 pl\#14 x L-006) & Híb. Experimental & 100,0 & 0,0 & $\mathrm{~S}$ \\
\hline F1(PIX-022E31 pl\#14 x MYR-29) & Híb. Experimental & 100,0 & 0,0 & $\mathrm{~S}$ \\
\hline
\end{tabular}

1 - Médias de quatro repetições.

2 - Avaliação final realizada aos 14 dias após a inoculação.

$3-\mathrm{R}=$ resistente; $\mathrm{S}=$ suscetível. 
Do total de híbridos avaliados, 20 foram classificados como suscetíveis à inoculação com $P$. capsici. Além do híbrido comercial Atenas F1 (Horticeres/Seminis), três outros híbridos experimentais apresentaram baixas incidências da doença e foram classificados como resistentes F1(PIM -013 x L -004); F1(PIM -013 x L -006); F1(PIM -013 x MYR -29) (Tabela 1). Todos esses híbridos tinham como um dos parentais a linhagem resistente PIM013, demonstrando que mesmo em condição heterozigota $\mathrm{o}(\mathrm{s})$ alelo(s) do(s) gene(s) que controla(m) a reação de resistência dessa linhagem foram efetivos nas atuais condições experimentais.

As progênies PIX 030pl\#03-02 e PIX 030pl\#06-03 ambas oriundas de CM-334 foram resistentes a $P$. capsici. Essas progênies poderão resultar em novas linhagens que poderão ser utilizadas como fonte de resistências a esse patógeno.

Uma alternativa para se obter híbridos com maior nível de resistência genética a $P$. capsici é duas linhagens resistentes para a obtenção de híbridos. Nessa condição recupera-se a condição homozigota dos genes de resistência (em caso de alelismo), ou se promove a piramidação dos diferentes genes de resistência (em caso de não alelismo). Isso poderia levar a genótipos comerciais efetivos contra um maior número de isolados desse patógeno.

O método de inoculação utilizado reproduz as condições ideais para ocorrência da doença, como a presença de água livre, alta temperatura, isolado altamente virulento e viável (HENZ \& LIMA, 1994). Além do mais, a tolerância das plantas inoculadas com $P$. capsici aumenta em estádios mais avançados de desenvolvimento da planta (MCGRATH \& SUPERAK, 1996), o que aumenta a chance dos genótipos classificados como resistentes realmente se comportarem como tal no campo, uma vez que se testaram jovens, ou seja, nos estádios em que são supostamente mais suscetíveis ao ataque do patógeno.

Na Tabela 2, estão os resultados da reação a PepYMV. A análise de grupamento permitiu separar a reação dos 32 tratamentos em três classes distintas. Nas testemunhas suscetíveis, $100 \%$ das plantas com sintomas típicos da doença (mosaico amarelo seguido ou não por deformação foliar, com notas médias superiores a 4,0) ao final do experimento (Classe III). Comportamento semelhante foi obtido em plantas de três outras linhagens experimentais testadas, com incidência superior a $85 \%$ (Classe III). Por outro lado, nas testemunhas resistentes, não foi observada nenhuma planta doente (Classe I) (Tabela 2).
Entre os híbridos comerciais apenas Magali R foi resistente a PepYMV. Os demais híbridos comerciais (Fortuna Super e Atenas F1) apresentaram 100\% das plantas com sintomas típicos da doença ao final das avaliações (Classe III) (Tabela 2).

Comportamento variável foi observado entre os híbridos experimentais avaliados para PepYMV (Tabela 2). Desses, 15 foram suscetíveis (notas médias superiores a 4,0) (Classe III). Outros cinco, entretanto, todos tendo como um dos genitores a linhagem MYR-29, foram resistentes com incidência da doença variando de 0,0 a 22,9\% (Tabela 2). Incidência maior foi obtida no híbrido F1(L-005 x MYR29), que apesar de ter como um dos genitores a linhagem MYR-29, apresentou 50\% das plantas avaliadas com notas superiores a 3,0 e nota média 2,8 (Classe II), sendo por isso classificado como moderadamente resistente.

Estudos têm demonstrado que a linhagem MYR-29 apresenta resistência do tipo monogênica e dominante a PepYMV (ECHER \& COSTA, 2002), o que está de acordo com os resultados aqui obtidos. Percebe-se, entretanto, que a incidência de PepYMV nos híbridos com MYR-29, em condições de inoculação artificial, parece depender também do parental suscetível. Alternativamente, outra explicação para a reação anômala do híbrido F1(L-005 x MYR-29) seria a possibilidade de que o acesso comercial de MYR-29 usado na obtenção dos híbridos aqui avaliados possa ter freqüência de plantas resistentes inferior a $100 \%$.

Nas testemunhas resistentes (CM-334 e nas progênies PIX 030 pl\#03-02 e PIX 030pl\#06-03), observouse a ocorrência de sintomas típicos de hipersensibilidade do tipo necrose sistêmica, seguido ou não pela queda das folhas inoculadas. Esse fato ocorreu possivelmente pelo fato do(s) alelo(s) do(s) genes que conferem a reação de resistência estarem em homozigose ou atuarem e interagirem de forma diferenciada. Em trabalho semelhante de avaliação de genitores a PepYMV, Echer \& Costa (2002) obtiveram resultados similares ao aqui observados para alguns genótipos avaliados.

Trabalhos relatando a identificação de fontes de resistência em pimentão a $P$. capsici e PepYMV mostram a existência de grupos de genes (CARANTA et al., 1999; GRUBE \& RADWANSKI, 2000; THABUIS et al., 2004). Nesse aspecto, as progênies originárias de CM-334 (PIX$030 \mathrm{pl} \# 03-02$ e PIX-030 pl\#06-03) resistentes tanto a $P$. capisici quanto a PepYMV são promissoras e podem ser utilizadas para desenvolver novos híbridos resistentes em programas de melhoramento genético. Além disso, atualmente o acesso CM-334 tem mostrado resistência também a nematóides de galhas do gênero Meloidogyne. 
TABELA 2 - Incidência de mosaico em mudas de pimentão inoculadas com PepYMV em bandejas de isopor de 128 células. Lavras, UFLA, 2003.

\begin{tabular}{|c|c|c|c|c|}
\hline Materiais testados & Tipo & Incidência (\%) & $\begin{array}{c}\text { Média das } \\
\text { Notas }^{2}\end{array}$ & Classe $^{3} /$ Reação $^{4}$ \\
\hline \multicolumn{5}{|l|}{ Testemunhas resistentes: } \\
\hline Criollo de Morelos 334 & Linhagem & $0,0 \pm 0,0$ & $1,0 \pm 0,0$ & $\mathrm{I} / \mathrm{R}$ \\
\hline Magali-R F1 (Sakata Sudamerica) & Híb. Comercial & $0,0 \pm 0,0$ & $1,0 \pm 0,0$ & $\mathrm{I} / \mathrm{R}$ \\
\hline PIX-030 pl\#03-02 & Família $\mathrm{F}_{2: 4}$ & $0,0 \pm 0,0$ & $1,0 \pm 0,0$ & $\mathrm{I} / \mathrm{R}$ \\
\hline PIX-030 pl\#06-03 & Família $\mathrm{F}_{2: 4}$ & $0,0 \pm 0,0$ & $1,0 \pm 0,0$ & $\mathrm{I} / \mathrm{R}$ \\
\hline \multicolumn{5}{|l|}{ Testemunhas suscetíveis: } \\
\hline PIM-013 & Linhagem & $100,0 \pm 0,0$ & $4,8 \pm 0,3$ & $\mathrm{III} / \mathrm{S}$ \\
\hline PIM-014 & Linhagem & $100,0 \pm 0,0$ & $4,6 \pm 0,0$ & $\mathrm{III} / \mathrm{S}$ \\
\hline \multicolumn{5}{|l|}{ Linhagens e Híbridos avaliados: } \\
\hline LINHA-003 & Linhagem & $91,7 \pm 11,8$ & $4,5 \pm 0,7$ & $\mathrm{III} / \mathrm{S}$ \\
\hline LINHA-004 & Linhagem & $85,7 \pm 20,2$ & $4,4 \pm 0,8$ & $\mathrm{III} / \mathrm{S}$ \\
\hline LINHA-006 & Linhagem & $92,9 \pm 10,1$ & $4,4 \pm 0,8$ & $\mathrm{III} / \mathrm{S}$ \\
\hline Fortuna Super F1 (Agristar) & Híb. Comercial & $100,0 \pm 0,0$ & $4,9 \pm 0,1$ & III/S \\
\hline Atenas F1 (Seminis) & Híb. Comercial & $100,0 \pm 0,0$ & $4,9 \pm 0,0$ & $\mathrm{III} / \mathrm{S}$ \\
\hline F1(HERCULES x L-004) & Híb. Experimental & $100,0 \pm 0,0$ & $4,9 \pm 0,1$ & $\mathrm{III} / \mathrm{S}$ \\
\hline F1 (L006 x L004) & Híb. Experimental & $100,0 \pm 0,0$ & $4,9 \pm 0,2$ & $\mathrm{III} / \mathrm{S}$ \\
\hline F1(L-3509 x L-004) & Híb. Experimental & $100,0 \pm 0,0$ & $4,6 \pm 0,2$ & $\mathrm{III} / \mathrm{S}$ \\
\hline F1(L-005 x L-004) & Híb. Experimental & $100,0 \pm 0,0$ & $4,8 \pm 0,3$ & $\mathrm{III} / \mathrm{S}$ \\
\hline F1(L-005 x L-006) & Híb. Experimental & $100,0 \pm 0,0$ & $4,7 \pm 0,1$ & $\mathrm{III} / \mathrm{S}$ \\
\hline F1(L-005 x MYR-29) & Híb. Experimental & $50,0 \pm 0,0$ & $2,8 \pm 0,3$ & II/MR \\
\hline F1(PIM-013 x L-004) & Híb. Experimental & $93,8 \pm 8,80$ & $4,7 \pm 0,3$ & III/S \\
\hline F1(PIM-013 x L-006) & Híb. Experimental & $92,9 \pm 10,1$ & $4,7 \pm 0,5$ & $\mathrm{III} / \mathrm{S}$ \\
\hline F1(PIM-013 x MYR-29) & Híb. Experimental & $0,0 \pm 0,0$ & $1,0 \pm 0,0$ & $\mathrm{I} / \mathrm{R}$ \\
\hline F1(PIM-014 x L-004) & Híb. Experimental & $100,0 \pm 0,0$ & $5,0 \pm 0,0$ & III/S \\
\hline F1(PIM-014 x L-006) & Híb. Experimental & $91,7 \pm 11,8$ & $4,7 \pm 0,5$ & $\mathrm{III} / \mathrm{S}$ \\
\hline F1(PIM-014 x MYR-29) & Híb. Experimental & $22,9 \pm 14,7$ & $1,9 \pm 0,6$ & $\mathrm{I} / \mathrm{R}$ \\
\hline F1(MAGDA x L-004) & Híb. Experimental & $87,5 \pm 23,0$ & $4,4 \pm 0,9$ & $\mathrm{III} / \mathrm{S}$ \\
\hline F1(MAGDA x L-006) & Híb. Experimental & $90,0 \pm 10,0$ & $4,3 \pm 0,8$ & III/S \\
\hline F1(MAGDA x MYR-29) & Híb. Experimental & $0,0 \pm 0,0$ & $1,0 \pm 0,0$ & $\mathrm{I} / \mathrm{R}$ \\
\hline F1(PIX-021G 0818 pl\#01 x L-004) & Híb. Experimental & $100,0 \pm 0,0$ & $4,9 \pm 0,1$ & $\mathrm{III} / \mathrm{S}$ \\
\hline F1(PIX-021G 0818 pl\#01 x L-006) & Híb. Experimental & $100,0 \pm 0,0$ & $4,8 \pm 0,1$ & III/S \\
\hline F1(PIX-021G 0818 pl\#01 x MYR-29) & Híb. Experimental & $16,7 \pm 20,0$ & $1,6 \pm 0,8$ & $\mathrm{I} / \mathrm{R}$ \\
\hline F1(PIX-022E31 pl\#14 x L-004) & Híb. Experimental & $100,0 \pm 0,0$ & $4,9 \pm 0,1$ & $\mathrm{III} / \mathrm{S}$ \\
\hline F1(PIX-022E31 pl\#14 x L-006) & Híb. Experimental & $100,0 \pm 0,0$ & $4,9 \pm 0,1$ & $\mathrm{III} / \mathrm{S}$ \\
\hline F1(PIX-022E31 pl\#14 x MYR-29) & Híb. Experimental & $10,0 \pm 14,0$ & $1,4 \pm 0,4$ & $\mathrm{I} / \mathrm{R}$ \\
\hline
\end{tabular}

1 - Médias e desvio padrão das incidências obtidas de duas repetições com oito plantas cada.

2 - Médias e desvio padrão das notas obtidas de duas repetições com oito plantas cada, em que: 1=sem sintomas; 2=clareamento de nervuras; $3=$ mosaico leve; 4=mosaico bem desenvolvido, sem deformação foliar; 5=mosaico amarelo, bolhoso, com deformação foliar.

3 - Classes determinadas através de agrupamento das médias.

$4-\mathrm{R}=$ resistente; $\mathrm{MR}=$ moderadamente resistente; $\mathrm{S}=$ suscetível. 


\section{CONCLUSÕES}

Criollo de Morellos 334, PIM-013 e as progênies PIX-03 pl\#03-2 e PIX-030 pl\#06-3, o híbrido Atenas e outros 3 híbridos experimentais que tinham como um dos parentais a linhagem PIM-013, foram resistentes a $P$. capsici.

Resistência a PepYMV foi encontrada no acesso Criollo de Morellos 334, nas progênies PIX-03 pl\#03-2 e PIX-030 pl\#06-3 e no híbrido comercial Magali R. Além desses, outros 6 híbridos experimentais, que tinham como um dos parentais a linhagem MYR-29, também se mostraram resistentes.

Resistência a ambos os patógenos foi encontrada nas famílias PIX-03 pl\#03-2 e PIX-030 pl\#06-3 e no híbrido experimental F1(PIM-013 x MYR-29).

\section{AGRADECIMENTOS}

Os autores expressam seus agradecimentos ao CNPq (Conselho Nacional de Desenvolvimento Científico e Tecnológico), FAEPE/UFLA (Fundação de Apoio ao Ensino, Pesquisa e Extensão / Universidade Federal de Lavras), FAPEMIG (Fundação de Amparo à Pesquisa do Estado de Minas Gerais), CAPES/MEC (Coordenação de Aperfeiçoamento de Pessoal de Nível Superior), HortiAgro Sementes Ltda, Sakata Sudamerica, e a pesquisadora da Embrapa Hortaliças - CNPH, Dra ${ }^{a}$. Alice K. Inoue-Nagata.

\section{REFERÊNCIAS BIBLIOGRÁFICAS}

BOITEUX, L. S.; CUPERTINO, F. P.; SILVA, C.; DUSI, A. N.; MONTE-NESHICH, D. C. Resistance to Potato virus $Y$ (pathotype 1-2) in Capsicum annuum and Capsicum chinense is controlled by two independent major genes. Euphytica, Wageningen, v. 87, p. 53-58, 1996.

CAFÉ FILHO, A. C.; DUNIWAY, J. M.; DAVIS, R. M. Effects of the frequency of furrow irrigation on root and fruit rots of squash caused by Phytophthora capsici. Plant Disease, Quebec, v. 79, p. 44-48, 1995.

CARANTA, C.; THABUIS, A.; PALLOIX, A. Development of a CAPS marker for the Pvr4 locus: a tool for pyramiding potyvirus resistance genes in pepper. Genome, Ottawa, v. 42, p. 1111-1116, 1999.

ECHER, M. M.; COSTA, C. P. Reaction of sweet pepper to the potato virus $Y\left(\mathrm{PVY}^{\mathrm{M}}\right)$. Scientia Sgricola, Piracicaba, v. 59, n. 2, p. 309-314, 2002.
GIL-ORTEGA，R.; PALAZOÓN-ESPAÑOL，C.; CUARTERO-ZUECO, J. Genetics of the resistance to Phytophthora capsici in the pepper line 'SCM334'. Plant Breeding, Berlin, v. 107, n. 1, p. 50-55, 1991.

GIL-ORTEGA, R.; PALAZOÓN-ESPAÑOL, C.; CUARTERO-ZUECO, J. Genetics relations ships among four pepper genotypes resistant to Phytophthora capsici. Plant Breeding, Berlin, v. 108, n. 1, p. 118-125, 1992.

GIL-ORTEGA, R.; PALAZOÓN-ESPAÑOL, C.; CUARTERO-ZUECO, J. Interactions in the pepper Phytophthora capsici system. Plant Breeding, Berlin, v. 114, n. 1, p. 74-77, 1995.

GRUBE, R.; RADWANSKI, J. A. H. N. M. Comparative analysis of disease resistance in the Solanaceae. Genetcs, [S.1.], v. 155, p. 873-887, 2000.

GUBLER, W. D.; DAVIS, R. M. Phytophthora crown and root rot. In: ZITTER, T. A.; HOPKINS, D. L.; THOMAS, C. E. (Eds.). Compendium of cucurbit diseases. Saint Paul: APS, 1996. p. 19-20.

GUERRERO-MORENO, A.; LABORDE, J. A. Current status of pepper breeding for resistance to Phytophthora capsici in Mexic. In: EUCARPIA MEETING ON GENETICS BREEDING OF CAPSICUM, 4., 1980, Wageningen, Holanda. Proceedings... Wageningen: IVT, 1980. p. 52-56.

HENZ, G. P.; LIMA, M. F. Avaliação de fatores que afetam a reação de Cucurbita spp. a Phytophthora capsici. Fitopatologia Brasileira, Brasília, v. 19, n. 4, p. 560-565, 1994.

INOUE-NAGATA, A. K.; FONSECA, M. E. N.; RESENDE, R. O.; BOITEUX, L. S.; MONTE, D. C.; DUSI, A. N.; ÁVILA, A. C.; VLUGT, R. A. A. van der. Pepper yellow mosaic virus, a new potyvirus in sweetpepper, Capsicum annuиm. Archives of Virology, [S.1.], n. 147, p. 849-855, 2002.

KOBORI, R. F.; DELLA-VECHIA, P. T.; KUROZAWA, C.; SOLER, J. M. P. Avaliação da resistência de linhagens de Casicum annuum quando inoculadas com três concentrações de inóculo de Phytophthora capsici. Summa Phytopathologica, Jabotiabal, v. 26, n. 1, p. 77-81, 2000 . 
KYLE, M. M.; PALLOIX, A. Proposed revision of nomenclature for Potyvirus resistance genes in Capsicum. Euphytica, Wageningen, v. 97, p. 183-188, 1997.

LEITE, R. V. S. Mapeamento das regiões genômicas que conferem resistência a requeima, causada pôr Phytophthora capsici, na linhagem de pimentão L-3436. 1999. 44 f. Dissertação (Mestrado em Fitopatologia) Universidade Federal de Viçosa, Viçosa, 1999.

LUZ, E. D. M. N.; CERQUEIRA, A. O.; FALEIRO, F. G.; DANTAS NETO, A.; MATUSUOKA, K.; MARQUES, J. R. B. Diversidade genética de isolados de Phytophthora capsici de diferentes hospedeiros com base em marcadores RAPD, patogenicidade e morfologia. Fitopatologia Brasileira, Brasília, v. 28, n. 5, p. 559-564, 2003.

MACIEL-ZAMBOLIM, E.; COSTA, H.; CAPUCHO, A. S.; ÁVILA, A. C. de; INOUE-NAGATA, A. K.; KITAGIMA, E. W. Surto epidemiológico do vírus do mosaico amarelo do pimentão em tomateiro na região serrana do Espírito Santo. Fitopatologia Brasileira, Brasília, v. 29, n. 3, p. 325-327, 2004.

McGRATH, M. T.; SUPERAK, T. H. Sensitivity of Cucurbita pepo experimentals and varieties to Phytophthora crown rot and fruit rot. Biological and Cultural Tests, [S.1.], v. 11, p. 116, 1996.

PALlOIX, A.; DAUBÈZE, A. M.; POCHARD, E. Phytophthora root rot of pepper: influence of host genotype and pathogen strain on the inoculum density: desease severity relathionships. Journal of Phytophathology, Berlin, v. 123, n. 1, p. 25-33, 1988.

PRINCE, J. P.; SCOTT, P. E.; SIDHU, G.; MYERS, P. A. Genetics resistance in pepper to Phytophthora capsici: scar markerers and hot-pathogen interactions. In: PLANT \& ANIMAL GENOME, 9., 2001, San Diego, CA, EUA. Proceedings... San Diego: USDA/ISPBM, 2001. Disponível em: : <http://Www.intl-pag.org/pag/9/abstracts 'P 5 g_ 14.htm|>. Acesso em: 8 fev. 2004.
REIFSCHNEIDER, F. J. B. (Org.). Capsicum . pimentas e pimentões no Brasil. Brasília, DF: Embrapa Comunicação para Transferência de Tecnologia/Embrapa Hortaliças, 2000. $113 \mathrm{p}$.

RISTAINO, J. B.; JOHNSTON, S. A. Ecologically based aproaches to management of Phytophthora blight on bell pepper. Plant Disease, Saint Paul, v. 83, n. 12, p. 1080-1089, 1999.

SARAIVA, T. C. R. B. Herança da resistência à murcha do pimentão (Capsicm annuum L.) causada pôr Phytophthora capsici Leonian. 1982. 40 f. Dissertação (Mestrado em Genética e Melhoramento de Plantas) Universidade Federal de Viçosa, Viçosa, 1982.

THABUIS, A.; PALLOIX, A.; SERVIN, B.; DAUBÈZE, A. M.; SIGNORET, P.; HOSPITAL, F.; LEFEBVRE, V. Markerassisted introgression of 4 Phytophthora capsici resistance QTL alleles into a bell pepper line: validation of additive and epistatic effects. Molecular Breeding, [S.1.], v. 1, p. 9-20, 2004.

TRUTA, A. A. C.; SOUZA, A. R. R.; NASCIMENTO, A. V. S.; PEREIRA, R. C.; PINTO, C. M. F.; BROMMONSCHENKEL, S. H.; CARVALHO, M. G.; ZERBINI, F. M. Identidade e propriedades de isolados de isolados de potyvirus provenientes de Capsicum spp. Fitopatologia Brasileira, Brasília, v. 29, n. 2, p. 160-168, 2004.

URBEN, A. F. Phytophthora capsici, agente etiológico da murcha em Capsicum annuum em Minas Gerais. 1980. 63 f. Dissertação (Mestrado em Fitopatologia) Universidade Federal de Viçosa, Viçosa, 1982.

VALLE, L. A. C. Análise genética e identificação de regiões genômicas que conferem resistência a Phytophthora capsici em "Criollo de Morellos 334" (Capsicum annuum). 2001. 85 f. Tese (Doutorado em Fitopatologia) Universidade Federal de Viçosa, Viçosa, 2001. 